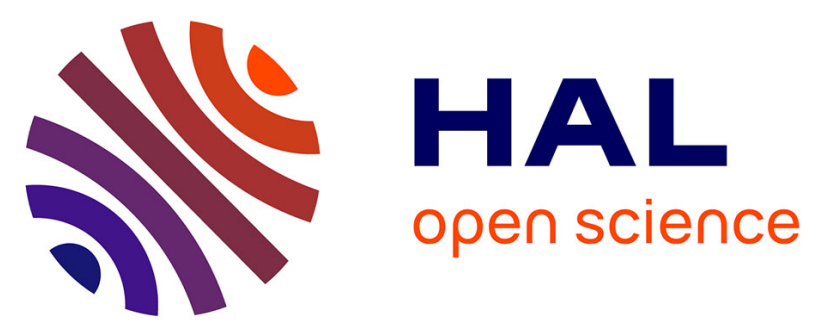

\title{
HCI Ethics, Privacy, Accessibility, and the Environment: A Town Hall Forum on Global Policy Issues
}

Lorraine Kisselburgh, Michel Beaudouin-Lafon, Lorrie Faith Cranor, Jonathan Lazar, Vicki Hanson

\section{To cite this version:}

Lorraine Kisselburgh, Michel Beaudouin-Lafon, Lorrie Faith Cranor, Jonathan Lazar, Vicki Hanson. HCI Ethics, Privacy, Accessibility, and the Environment: A Town Hall Forum on Global Policy Issues. CHI '20 - 38th SIGCHI conference on Human Factors in computing systems, May 2020, Honolulu, HI, USA, United States. pp.1-6, 10.1145/3334480.3381067 . hal-02867302

\section{HAL Id: hal-02867302 https://hal.science/hal-02867302}

Submitted on 14 Jun 2020

HAL is a multi-disciplinary open access archive for the deposit and dissemination of scientific research documents, whether they are published or not. The documents may come from teaching and research institutions in France or abroad, or from public or private research centers.
L'archive ouverte pluridisciplinaire HAL, est destinée au dépôt et à la diffusion de documents scientifiques de niveau recherche, publiés ou non, émanant des établissements d'enseignement et de recherche français ou étrangers, des laboratoires publics ou privés. 


\section{HCI Ethics, Privacy, Accessibility, and the Environment: A Town Hall Forum on Global Policy Issues}

$\begin{array}{ll}\begin{array}{l}\text { Lorraine Kisselburgh } \\ \text { Purdue University, } \\ \text { West Lafayette, IN, USA } \\ \text { lorraine@purdue.edu }\end{array} & \begin{array}{l}\text { Jonathan Lazar } \\ \text { University of Maryland } \\ \text { College Park, MD, USA } \\ \text { jlazar@umd.edu }\end{array} \\ \begin{array}{l}\text { Michel Beaudouin-Lafon } \\ \text { Université Paris-Saclay }\end{array} & \begin{array}{l}\text { Vicki L. Hanson } \\ \text { (moderator) }\end{array} \\ \text { Orsay, France } & \text { Association for Computing } \\ \text { mbl@Iri.fr } & \text { Machinery (ACM) } \\ \text { Lorrie Cranor } & \text { New York, NY, USA } \\ \text { Carnegie Mellon University } & \text { vicki.hanson@acm.org } \\ \text { Pittsburgh, PA, USA } & \\ \text { lorrie@cmu.edu } & \end{array}$

Permission to make digital or hard copies of part or all of this work for personal or classroom use is granted without fee provided that copies are not made or distributed for profit or commercial advantage and that copies bear this notice and the full citation on the first page. Copyrights for third-party components of this work must be honored. For all other uses, contact the owner/author(s).

CHI'20 Extended Abstracts, April 25-30, 2020, Honolulu, HI, USA (C) 2020 Copyright is held by the owner/author(s).

ACM ISBN $978-1-4503-6819-3 / 20 / 04$

https://doi.org/10.1145/3334480.3381067

\begin{abstract}
We seek to engage a broad and diverse audience in discussing emerging challenges in $\mathrm{HCI}$ technologies that have potential for significant social impact. In a town hall forum, members of the ACM Technology Policy Council will introduce four emerging challenges for discussion: ethical HCI in global contexts; privacy protection in human-AI interaction; accessible interactions in $\mathrm{HCI}$ design; and the environmental impact of HCI. Discussion will be launched with a question from the panel; additional questions will be posted and ranked from the audience. The session will support digital and remote audience participation, and participants will have access to a summary report when the session concludes. These discussions provide an opportunity for $\mathrm{CHI}$ members to contribute to emerging policy and governing environments to facilitate ethical, accessible, and environmentally sensitive HCI research, design, and development.
\end{abstract}

\section{Author Keywords}

HCI; Ethics; Privacy; Environment; Social Impact; Policy. 


\begin{tabular}{|l} 
Key ACM Policy \\
Statements and Reports \\
www.acm.org/public-policy \\
\\
Statement on the Importance of \\
Preserving Personal Privacy \\
(USTPC 2018) \\
Statement on Accessibility, \\
Usability, and Digital \\
Inclusiveness (USTPC 2017) \\
Statement on Internet of Things \\
Privacy and Security (USTPC \& \\
Europe TPC 2017) \\
Statement on Algorithmic \\
Transparency and Accountability \\
(USTPC \& Europe TPC 2017) \\
Statement on Computing and \\
Network Security (USTPC 2017) \\
Statement on Mandatory \\
Engineered LE Access to \\
Information Infrastructure and \\
Devices (USTPC 2018) \\
Email and Internet Voting: The \\
Overlooked Threat to Election \\
Security (USTPC 2018) \\
ACM Code of Ethics and \\
Professional Conduct \\
\end{tabular}

\section{CSS Concepts \\ - Human-centered computing Human computer interaction (HCI) - Social and professional topics Computing / technology policy}

\section{Introduction}

The CHI community has a strong tradition of interrogating the social, ethical, and political implications of their research and technologies. In the past decade, $\mathrm{CHI}$ panels and papers have engaged in discussion of topics such as environmental impact [1, $5,8,11,16,17]$, accessibility [9], privacy [12], and research ethics $[3,5]$, and published an important monograph on the policy implications of $\mathrm{HCI}$ technologies [13]. Members of the CHI community have also served important roles on national and international policy councils and commissions throughout the world, such as the Federal Trade Commission in the US.

These and other efforts demonstrate the strong commitment of $\mathrm{CHI}$ community members to social good and public engagement $[2,14]$.

However, research suggests that only $5 \%$ of policy documents produced in U.S. Congress in the last 15 years included citations to primary research [18], an alarming gap. This comes at a time that major legislation and regulatory actions are being developed around the globe. For example, the 2019 G20 summit in Japan included an endorsement of OECD's universal principles for AI [15] that will serve to inform legislation in many countries.

In an increasingly complex, global, and ubiquitous technological landscape, bridging the expertise of $\mathrm{CHI}$ members with those responsible for policy is critically important. The HCI and greater ACM community has a unique opportunity to help shape emerging policy around AI and interactive technologies, and provide the technical expertise required to develop policy that optimizes the opportunities and minimizes the risks of emerging technologies. These laws, regulations, and policies in turn affect the research and practices of $\mathrm{HCI}$ researchers and professionals. For example, changing IRB regulatory frameworks for research with human participants, a new Code of Ethics with guidelines for ACM professionals, and recently passed legislation in Europe (GDPR) [7] and the state of California (CCPA) [4] regarding data collection and informed consent practices for applications and platforms, all have significant impact on research and design of $\mathrm{HCI}$ technologies.

This year ACM established the Technology Policy Council to engage with issues such as these in countries and governing bodies around the world. Our policy committees address longstanding issues of privacy and security, and emerging issues of algorithmic transparency and accountability, bias, and the environmental impact of computational research and practice [see sidebar]. In this town hall session, Council members will facilitate discussion on key emerging challenges.

\section{Emerging Challenges}

Our goal is to engage a broad and diverse audience in discussing emerging challenges in $\mathrm{HCI}$ technologies that have potential for significant social impact. These discussions inform our opportunities to contribute to policy and governing environments that facilitate 
ethical, accessible, and environmentally sensitive $\mathrm{HCI}$ research, design, and development.

We will organize the town hall discussion around four themes: a) Ethical $\mathrm{AI}$ and $\mathrm{HCI}$; b) Privacy protections in human-AI interactions; c) Accessible interactions in $\mathrm{HCI}$ design; and d) $\mathrm{HCI}$ and the environmental impact of ICT.

\section{Ethical $A I$ and $H C I$}

We will discuss a challenging global issue: differing cultural norms of human-computer and human-AI interaction. Using two cases - facial recognition systems and biometric data systems - we will discuss the variance in attitudes and cultural norms toward governance of AI in international contexts. We ask: How do we create ethical guidelines, standards, and governance for HCI and AI technologies that are culturally sensitive, yet protective of universallyrecognized human rights?

\section{Privacy protection in human-AI interactions} New privacy laws around the world require organizations to be transparent about their data collection practices and offer people the opportunity to make choices about the use of their data. However, privacy notices are often difficult to read and people don't understand how to use privacy controls or what they actually do. HCI researchers and practitioners can play a role not only in developing more usable privacy user experiences, but also in educating policy makers about how to shape requirements that are likely to result in usable and useful privacy transparency and control mechanisms.
Furthermore, while legislative decisions about data protection and privacy continue to be debated, especially with the passage of GDPR and CCPA, emerging contexts for social interaction and data collection are being designed under the advent of artificial intelligence and robotics. We pose the following questions for $\mathrm{HCI}$ designers and researchers: How do we design human-AI interfaces in ways that are sensitive to the protection of privacy, as well as to norms of data protection? What issues regarding privacy protection should be identified in regulatory and policy development? In what way do human-AI interactions introduce new risks to privacy?

3. Accessible interactions in HCI design Around the world, many countries have laws and/or policies requiring that certain categories of digital content and/or devices be accessible for people with disabilities. The most common requirement is that government web sites must be accessible, but other countries have requirements that business websites must also be accessible. Furthermore, technologies procured by government frequently must be accessible and in some countries, even telecommunications devices sold to the public must be accessible. Technical standards and guidelines used for accessibility compliance across the world (e.g. the Web Content Accessibility Guidelines, and epub3), and various types of laws and requirements, will be discussed, as well as international treaties such as the UN Convention on the Rights of Persons with Disabilities. We will ask: What emerging challenges around accessibility arise in the design and governance of HCI and human-AI interaction technologies? 
4. HCI and the environmental impact of ICT The information and communication technology (ICT) sector is estimated to be responsible for $4 \%$ of greenhouse gas emissions, higher even than air traffic. As the fastest growing sector ( $8 \%$ annually), ICT will soon exceed even road transportation emissions. The main causes of emissions are data centers, data science and AI, blockchain, video streaming, and the internet of things. Production and shipping of computers are also important sources of emissions, and many materials, including rare earths, and are not well recycled. Although ICT is becoming more energy efficient, these savings are offset by increased use, leading to rebound and backfire effects, as the overal energy consumption actually increases with each progress in efficiency. As HCI researchers and practitioners, we ask, how can we: a) design systems that encourage more frugal use of computing and communication resources; $b$ ) create tools that help users be aware of the environmental impact of their digital lives; and c) envision policy activities to reduce emissions?

\section{Format}

This session will be presented in a town hall format, to maximize engagement of attendees with most of the time committed to questions, comments, and debate. The panelists will include members of the global ACM Technology Policy Council and its US committee, and will be moderated by ACM's Chief Executive Officer.

The session will begin with a brief introduction of the panelists and key ACM policy activities, a discussion of engagement rules, and an overview of the themes to be discussed. The session will then proceed in four segments. Each segment will be introduced by a panelist, who will identify key issues and then pose three questions for audience discussion. The moderator will guide discussion, selecting additional questions that emerge from the audience, finding counterpoints where possible. Multiple microphones will be available in the audience to encourage engagement.

To broaden participation and interaction, both in-person and remotely, we will employ a web-based town hall platform to allow participants to pose, prioritize, and respond to questions throughout the discussions.

Through the use of online town hall software, we will:

1. Broaden audience participation and accessibility (and reduce carbon footprint);

2. Provide alternative means for questions to be introduced (facilitating more questions);

3. Support ranking of issues; and

4. Provide post-session analytics for future policy activities.

\section{Panelists and Moderator}

Lorraine Kisselburgh is Chair of the new global ACM Technology Policy Council, former member of the ACM Code of Ethics Task Force, and a Visiting Fellow at the Policy Research Institute and CERIAS (security and privacy) Center at Purdue University. Her research, funded by the US National Science Foundation and recognized by the National Academy of Engineering, focuses on the ethical and privacy implications of emerging technologies; creative collaboration in computer-supported teams; and gendered practices in technologies and careers.

Michel Beaudouin-Lafon is Professor of Computer Science at Université Paris-Saclay and a senior fellow of Institut Universitaire de France. His research interests 
include fundamental aspects of interaction, novel interaction techniques, computer-supported cooperative work and engineering of interactive systems. He has served on the ACM and ACM Europe Councils, and is vice-chair of the new ACM Technology Policy Council.

Lorrie Cranor is director of the CyLab Security and Privacy Institute at Carnegie Mellon University. Her research focusses on usable privacy and security. In 2016 she served as Chief Technologist at the United States Federal Trade Commission. She is a member of the new ACM Technology Policy Council.

Jonathan Lazar is a professor at the College of Information Studies, Associate Director of the Trace Center, and core faculty of the Human-Computer Interaction Lab, all at the University of Maryland. He has published 12 books, including "Research Methods in Human-Computer Interaction" (co-authored with Feng and Hochheiser, 2nd edition), "Ensuring Digital Accessibility through Process and Policy" (co-authored with Goldstein and Taylor), and Disability, Human Rights, and Information Technology (co-edited with Michael Stein). Dr. Lazar served as SIGCHI adjunct chair of public policy from 2010-2015, and was the recipient of the 2016 SIGCHI Social Impact Award.

Vicki Hanson (moderator) is Chief Executive Officer, and Past President of ACM. With funding from both national agencies (RCUK and NSF) and industry (IBM, Google), her research has focused on technology for people with disabilities, the aging population, and related research ethics. She is an ACM Fellow and member of the SIGCHI Academy.

\section{References}

[1] Oliver Bates, Mike Hazas, Adrian Friday, Janine Morley, and Adrian K. Clear. 2014. Towards an Holistic View of the Energy and Environmental Impacts of Domestic Media and IT. In Proceedings of the SIGCHI Conference on Human Factors in Computing Systems (CHI '14). ACM, New York, NY, USA, 1173-1182. DOI:

http://dx.doi.org/10.1145/2556288.2556968

[2] Steve Benford, Chris Greenhalgh, Bob Anderson, Rachel Jacobs, Mike Golembewski, Marina Jirotka, Bernd Carsten Stahl, Job Timmermans, Gabriella Giannachi, Matt Adams, Ju Row Farr, Nick

Tandavanitj Tandavanitj, and Kirsty Jennings.

2015. The Ethical Implications of HCI's Turn to the Cultural. ACM Transactions on Computer-Human Interaction. 22 (2015), 24:1-24:37. DOI: http://dx.doi.org/10.1145/2775107

[3] Amy Bruckman. 2014. Research Ethics and HCI. In Ways of Knowing in HCI, Judith S. Olson and Wendy A. Kellogg (Eds.). Springer New York, 449468. DOI: http://dx.doi.org/10.1007/978-1-49390378-8_18

[4] California Consumer Privacy Act (CCPA). 2018. Assembly Bill No. 375, Sec 1798.100 of California Civil Code.

[5] Janet Davis, Harry Hochheiser, Juan Pablo Hourcade, Jeff Johnson, Lisa Nathan, and Janice Tsai. 2012. Occupy CHI!: Engaging U.S. Policymakers. In CHI'12 Extended Abstracts on Human Factors in Computing Systems (CHI EA '12). ACM, New York, NY, USA, 1139-1142. DOI: http://dx.doi.org/10.1145/2212776.2212406

[6] Casey Fiesler, Jeff Hancock, Amy Bruckman, Michael Muller, Cosmin Munteanu, and Melissa Densmore. 2018. Research Ethics for HCI: A Roundtable Discussion. In CHI'18 Extended Abstracts on Human Factors in Computing Systems (CHI EA '18). ACM, New York, NY, USA. 
[7] General Data Protection Regulation (GDPR). 2016. Regulation (EU) 2016/679 of the European Parliament and of the Council on the protection of natural persons with regard to the processing of personal data and on the free movement of such data. OJ 2016 L119, 1-88.

[8] Elizabeth Goodman. 2009. Three Environmental Discourses in Human-computer Interaction. In CHI '09 Extended Abstracts on Human Factors in Computing Systems (CHI EA '09). ACM, New York, NY, USA, 2535-2544. DOI:

http://dx.doi.org/10.1145/1520340.1520358

[9] Jan Gulliksen, Hans von Axelson, Hans Persson, and Bengt Göransson. 2010. Accessibility and Public Policy in Sweden. interactions 17, 3 (May 2010), 26-29. DOI:

http://dx.doi.org/10.1145/1744161.1744168

[10] A. Jobin, M. Ienca, and E. Vayena. 2019. The global landscape of AI ethics guidelines. Nature Machine Intelligence, 1, 389-399.

[11] Bran Knowles, Lynne Blair, Paul Coulton, and Mark Lochrie. 2014. Rethinking Plan A for Sustainable HCI. In Proceedings of the 32nd Annual ACM Conference on Human Factors in Computing Systems (CHI '14). ACM, New York, NY, USA, 3593-3596. DOI: http://dx.doi.org/10.1145/2556288.2557311

[12] Julia Lane, Victoria Stodden, Stefan Bender, and Helen Nissenbaum (Eds.). 2014. Privacy, Big Data, and the Public Good: Frameworks for Engagement. Cambridge University Press, Cambridge.

[13] Jonathan Lazar, Julio Abascal, Simone Barbosa, Jeremy Barksdale, Batya Friedman, Jens Grossklags, Jan Gulliksen, Jeff Johnson, Tom McEwan, Loïc Martínez-Normand, Wibke Michalk, Janice Tsai, Gerrit van der Veer, Hans von Axelson, Ake Walldius, Gill Whitney, Marco Winckler, Volker Wulf, Elizabeth F. Churchill,
Lorrie Cranor, Janet Davis, Alan Hedge, Harry Hochheiser, Juan Pablo Hourcade, Clayton Lewis, Lisa Nathan, Fabio Paterno, Blake Reid, Whitney Quesenbery, Ted Selker, and Brian Wentz. 2016. Human-Computer Interaction and International

Public Policymaking: A Framework for

Understanding and Taking Future Actions.

Foundations and Trends in Human-Computer Interaction 9, 2 (2016), 69-149. DOI:

http://dx.doi.org/10.1561/1100000062

[14] Lisa P. Nathan and Batya Friedman. 2010. Interacting with Policy in a Political World: Reflections from the Voices from the Rwanda Tribunal Project. interactions 17, 5 (Sept. 2010), 56-59. DOI:

http://dx.doi.org/10.1145/1836216.1836231

[15] OECD Recommendation of the Council on Artificial Intelligence.https://legalinstruments. oecd.org/en/i nstruments/OECD-LEGAL-0449

[16] M. Six Silberman, Lisa Nathan, Bran Knowles, Roy Bendor, Adrian Clear, Maria Håkansson, Tawanna Dillahunt, and Jennifer Mankoff. 2014. Next Steps for Sustainable HCI. interactions 21, 5 (Sept. 2014), 66-69. DOI: http://dx.doi.org/10.1145/2651820

[17] Vanessa Thomas, Christian Remy, Mike Hazas, \& Oliver Bates. 2017. HCI and Environmental Public Policy: Opportunities for Engagement. In Proceedings of the CHI Conference on Human Factors in Computing Systems (CHI '17). pp. 6986-6992. DOI:

https://doi.org/10.1145/3025453.3025579

[18] I. Yanovitzky and Matt S. Weber. 2019. Analyzing Use of Evidence in Public Policymaking Processes: A Theory-Grounded Content Analysis Methodology. Evidence \& Policy. DOI: http://dx.doi.org/10.1332/174426418X15378680 726175 